\title{
FEAR OF FALL AMONG SUB-ACUTE STROKE PATIENTS IN LAHORE, PAKISTAN
}

\author{
Neelofar Rizwan', Arooj Fatima ${ }^{1 凶}$, \\ Maimoona Akhlaq Ahmed', Sana Tauqeer'
}

\begin{abstract}
OBJECTIVE: To compare fear of fall (lack of self-confidence to maintain balance during normal activity) with and without fall history among sub-acute stroke patients in Lahore, Pakistan.

METHODS: This cross-sectional study was conducted from October 2018 till January 2019 in different hospitals of Lahore, Pakistan. Sixty-six patients in age group of 40-75 years and having sub-acute stroke (stroke duration between 2-6 months) were included in the study after taking their consent. Fall Efficacy ScaleInternational (FES-I) questionnaire was used.
\end{abstract}

RESULTS: Out of 66 subjects, 4 I $(62.1 \%)$ were males. Majority $(n=39$; $59.1 \%$ ) of patients were between $50-70$ years of age and $16(24.2 \%)$ were $>70$ years old. Fifty $(75.8 \%)$ patients had hemorrhagic stroke. Most $(52 / 66,78.8 \%)$ of the patients were independent/ambulatory. Thirty-six (54.5\%) patients used assistive devices. Patients with history of fall were $37(56.1 \%)$ while fear of fall was recorded in 28 (42.4\%) patients. Maximum (17/37; 45.9\%) patients fell in washroom, 12/37 (32.4\%) in bedroom, 5/37 (12.5\%) fell outside at road or pavement and $3 / 37(8.1 \%)$ patients fell from stairs. Overall mean FES-I score was $29.08 \pm 5.29$. Mean FES-I score in patients with history of fall was $30.38 \pm 5.55$ as compared to $27.4 I \pm 4.50$ in patients with no fall history $(\mathrm{p}<0.05)$

CONCLUSION: In our study, fear of fall score is significantly higher in subacute stroke patients with history of fall than in patients without history of fall.

KEY WORDS: Stroke (MeSH); Falls (MeSH); Fear of fall (Non-MeSH); Fall selfefficacy (Non-MeSH); Fall related efficacy (Non-MeSH); Fall Efficacy ScaleInternational (Non-MeSH).

THIS ARTICLE MAY BE CITED AS: Rizwan N, Fatima A, Ahmed MA Tauqeer S. Fear of fall among sub-acute stroke patients in Lahore, Pakistan. Khyber Med Univ J 2020; I2(I): I5-8. DOI: I0.35845/kmuj.2020.19054.

\section{INTRODUCTION}

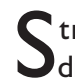
troke is the leading cause for disability now-a-days' and $80 \%$ of the individuals having stroke need help in performing a minimum of one purposeful movement from the day one. ${ }^{2}$ When stroke occurs, $40 \%$ individuals are unable to walk selfsufficiently in their societies. ${ }^{3}$ The person's ability to do work is frequently estimated in a clinic and after stroke, this ability is thought to be a serious element that influence movement. Self-efficacy is the person's confidence in his ability to accomplish a task and it is also associated to his self-confidence, enthusiasm, conduct and environment. ${ }^{4}$ Self-efficacy is well thought-out to be as significant as physical capability and helps in inducing judgments to participate in several events. After stroke, fall related self-efficacy was stated to be primarily compromised. Fear of falling was seen to improve during hospital stay rehabilitation and is related with improvements in motor activity $^{5,6}$ and walking capability. ${ }^{6}$

\section{The University of Lahore, Lahore, Pakistan. Email凶:aruj43@hotmail.com Contact \# : +92-341-4391882 \\ Date Submitted: February 20, 2019 Date Revised: January 18, 2020 \\ Date Accepted: January 24,2020}

Falls are the most common in all phases of stroke: the acute phase (less than 2 months duration), sub-acute phase (between 2-6 months duration), and chronic phase (more than 6 months duration). Aftermaths of falls include death or severe injury, minor injuries, functional restrictions, decreased motion \& movement and fear of falls. These consequences can have impact on person's independence and value of life. The remaining risk factors of falls along with deficiencies from stroke are power and balance reduction, neglect of the affected side, problems with awareness and difficulties in vision. These combinations may be the result of high occurrence of falls. ${ }^{7}$ It is stated that there is a great possibility of falls among the stroke survivors. ${ }^{8}$ Bandura presented the concept of self-efficacy and he is well-thought-out to be a significant instigator regarding human behaviors.' Factors, i.e. actions of everyday life routine, stability and cognition, were found to be discreetly associated with fear of falling. ${ }^{10}$ In patients with stroke, less attention has been given towards the improvement of the bodily function, the intellectual function and fall related self-efficacy. To assess fear of fall, Falls Efficacy Scale (FES) is one of the tools that was developed by Tinetti, et al." This Questionnaire was developed on the basis of concept of self-confidence relating to falls. ${ }^{12} \mathrm{~A}$ cross-sectional study on older adults shows that selfconfidence relating to fall is mediator of the relationship between fear of falling and functional ability. ${ }^{13}$ However, to our knowledge, no study was conducted to find the relationship of fear of fall with fall history among sub-acute stroke patients in our setup. Further, fear of fall, a psychological aftermath of fall, has not been studied as the factor which may result in future falls among sub-acute stroke population. 
TABLE I: DEMOGRAPHIC PROFILE OF THE STUDY SAMPLE $(\mathbf{N}=66)$

\begin{tabular}{|l|l|c|c|}
\hline \multicolumn{2}{|c|}{ Characteristics } & \multicolumn{1}{|c|}{$\begin{array}{c}\text { Frequency } \\
(\mathbf{n = 6 6 )}\end{array}$} & Percentage \\
\hline \multirow{3}{*}{ Age (years) } & $<50$ & $1 \mathrm{I}$ & 16.7 \\
\cline { 2 - 4 } & $50-70$ & 39 & 59.1 \\
\cline { 2 - 4 } & $>70$ & 16 & 24.2 \\
\hline \multirow{3}{*}{ Gender } & Male & 41 & 62.1 \\
\cline { 2 - 4 } & Female & 25 & 37.9 \\
\hline \multirow{2}{*}{ Marital Status } & Married & 53 & 80.3 \\
\cline { 2 - 4 } & Widowed & 13 & 19.7 \\
\hline \multirow{2}{*}{ Stroke Type } & Ischemic & 16 & 24.2 \\
\cline { 2 - 4 } & Hemorrhagic & 50 & 75.8 \\
\hline \multirow{2}{*}{ Stroke Site } & Left hemisphere & 31 & 47.0 \\
\cline { 2 - 4 } & Right hemisphere & 35 & 53.0 \\
\hline \multirow{2}{*}{ Assistive Device } & Yes & 36 & 54.5 \\
\cline { 2 - 4 } & No & 30 & 45.5 \\
\hline \multirow{2}{*}{ Fear of Fall } & Yes & 28 & 42.4 \\
\cline { 2 - 4 } & No & 38 & 57.6 \\
\hline \multirow{2}{*}{ Fall History } & Yes & 37 & 56.1 \\
\cline { 2 - 4 } & No & 29 & 43.9 \\
\hline
\end{tabular}

Therefore, we aimed to compare fear of fall among patients with and without fall history. The data in future can help to address high prevalence group of falls among sub-acute stroke patients by countering the fear using preventive and psychological measures.

\section{METHODS}

This cross-sectional study was initiated after taking proper ethical approval from institution review board (IRB) of The University of Lahore and 66 patients were enrolled conveniently after taking informed consent. The study was conducted from October 2018 till January 2019. Data was collected from different hospitals of Lahore i.e., General Hospital, Mayo Hospital, Water and Power Development Authority (WAPDA) Hospital and Pakistan Society for Rehabilitation of Disabled (PSRD).

The sample size of this study was 66 which was calculated by using sample size calculator Epi tool software online, where $P=0.25 \%$, i.e. proportion of people having stroke in Pakistani population as referenced as $250 / 100,000$ by Pakistan Stroke Society. $Z$ is significance level $(Z=1.96$ for $95 \%$ $\mathrm{Cl}$ ), $\mathrm{d}^{2}$ is the desired precision (half desired $\mathrm{Cl}$ ). The subjects between the within duration between 2-6 months (sub-acute) were included in the study. Subjects having neurological diseases other than stroke, lower extremity procedures or other surgeries during last 6 months were excluded.

Fall Efficacy Scale International (FES-I) questionnaire was used. This tool has sixteen items and scores are summed to calculate a range of total score from minimum 16 to maximum 64. Patients were asked to rate each activity on fourpoint scale, depending on how concerned they were that they might fall if they did that activity, regardless of whether they actually perform it. Items were scored between 1-4, where a score I if they were 'not at all concerned' while 4 if they were 'very concerned about that task'." Consent forms were signed by the subjects before giving them questionnaires. Descriptive statistics were calculated for all the variables including frequency and bar charts. To compare, independent t-test was used with a significant value of $\alpha=\leq 0.05$. Statistical analysis was performed by using SPSS

\section{RESULTS}

Out of 66 subjects included in study, 4I age of $40-75$ years and having stroke software package version 21 .
(62.1\%) were males. Eleven (16.7\%) subjects were less than 50 years, $39(59.1 \%)$ were between $50-70$ years. Patients with history of fall were 37 (56.1\%) while fear of fall was recorded in $28(42.4 \%)$ patients. Fifty $(75.8 \%)$ patients had hemorrhagic stroke (Table I). Most $(52 / 66,78.8 \%)$ of the patients were independent/ambulatory. Thirtysix $(54.5 \%)$ patients used assistive devices.

Patients with history of fall were 37 (56.1\%) while fear of fall was recorded in $28(42.4 \%)$ patients. Maximum (I7/37; 45.9\%) patients fell in washroom, 12/37 (32.4\%) in bedroom, $5 / 37$ (12.5\%) outside at road or pavement and $3 / 37(8.1 \%)$ felled from stairs.

Overall mean FES-I score was $29.08 \pm 5.29$. Mean FES-I score was $30.38 \pm 5.55$ in patients with history of fall as compared to $27.4 I \pm 4.50$ in patients with no fall history $(\mathrm{p}<0.05)$.

\section{DISCUSSION}

This cross-sectional study was conducted to find out the association of fear of fall with fall history among subacute stroke patients in Lahore, Pakistan. This study shows that there was a significant association between fear of fall and history of falls ( $p \leq 0.05)$. It was found that the patients had more falls in washroom and there were more falls in patients who used an ambulation device. The patients having fall history had low fall related self-efficacy: FES-I score $(30.38 \pm 5.55)$, where high FES-I score indicates low fall self-efficacy.

In this study, patients with fall history were $37(56.1 \%)$ and fear of fall was present in $28(42.4 \%)$ patients. A study conducted in America stated that the rate of fear of fall in the subjects was $66 \% .^{15}$ In another study, fear of fall was $48 \% .^{16}$ In a prospective observational study done in America, $45 \%$ of the subjects reported falling ${ }^{17}$ whereas, a study conducted in Kansas city, America reported fall rate to be $51 \% .^{18}$ The rate of fall described in these studies are relating to individuals with chronic stroke.

Present study stated that fall rate among patients was $56.1 \%$ whereas, a cross- 
sectional study conducted in American community of chronic stroke patients found fall rate to be $40 \% .{ }^{19}$ Fear of fall should be seen as the most appropriate for the beginning, contribution and life superiority of the patient. Fear of fall is considered as a crucial part for optimum outcome. We should adjust our tactics and methods as fear of fall may be an obstacle to the patient. This is very thought-provoking for exercise or for everyday workout of patients having stroke. Fear of fall is shared by most of the patients having acute ${ }^{20}$ and subacute stroke both. ${ }^{21,22}$

This research indicated that patients with high fall efficacy score on FES-I $(30.38 \pm 5.55)$ had a fall history. A study in Sydney, Australia was conducted which showed that in patients with the low fall efficacy score, the fall risk within 12 months for these patients was decreased to half than in patients whose score of fall efficacy was not decreased. ${ }^{23}$ Thus, the hospitals should have fall avoidance programs to begin there, and the interventions used should contain programs must consist of a diversity of methods and tactics. ${ }^{24}$ Another study conducted on the community of stroke patients in Taipei city, Taiwan stated that female gender, strong ADL dependency, and single falls were associated with high falls efficacy. ${ }^{25}$

In this study, fall history and fear of fall are dependent on each other $(P \leq 0.05)$ whereas, a case-control study conducted in Malaysia found that stroke patients were significantly more likely to be involved in recurrent falls and fear of falling $(P<.0 I)$ than non-stroke patients. ${ }^{26}$ In a study conducted among geriatric population in Rawalpindi and Islamabad, it was found that $79.7 \%$ had no history of fall, ${ }^{27}$ whereas in this study, conducted among stroke population between age $40-75$ years, $56.1 \%$ had a history of fall. In US and Britain, a study was conducted which gave us guiding principles to avoid falls. This study proposes us to make a method which will be more operative than a single treatment based on multiple factors like teaching and workout. It will also focus on the functional and emotional elements like fear of fall in the intervention for fall prevention. ${ }^{22}$

\section{LIMITATIONS}

This was a cross-sectional study limited to the hospitals of Lahore, Pakistan. The sample size was low, non-probability sampling was used and only the patients with sub-acute stroke were included. More researches are needed to relate different factors that may be the precursor of falls and to address the preventive measures needed to avoid falls.

\section{CONCLUSION}

The study concludes a significant difference between FES-I in patients with and without fall history. FES-I is significantly higher in sub-acute stroke patients with history of fall than in patients without history of fall.

\section{REFERENCES}

I. Billinger SA, Arena R, Bernhardt J, Eng JJ, Franklin BA, Johnson CM, et al. Physical activity and exercise recommendations for stroke survivors: a statement for healthcare professionals from the American Heart Association/ American Stroke Association. Stroke 20I4;45(8):2532-53. DOI: |0.1 |6I/STR.0000000000000022.

2. Joseph C, Rhoda A. Activity limitations and factors influencing functional outcome of patients with stroke following rehabilitation at a specialised facility in the Western Cape. Afr Health Sci 20I3;13(3): 646-54.

3. Lord SE, McPherson K, McNaughton HK, Rochester L, Weatherall M. Community ambulation after stroke: how important and obtainable is it and what measures appear predictive? Arch Phys Med Rehabil 2004; 85(2):234-9.

4. Barlow J. Self-efficacy in the context of rehabilitation. In: Stone JH, Blouin $M$, eds. International Encyclopedia of Rehabilitation. 2010.

5. Hellström K, Lindmark B, FuglMeyer A. The Falls-Efficacy Scale, Swedish version: does it reflect clinically meaningful changes after stroke? Disabil Rehabil 2002;24(9): $47|-8|$.
6. Hellstrom K, Lindmark B, Wahlberg $B$, Fugl-Meyer AR. Self-efficacy in relation to impairments and activities of daily living disability in elderly patients with stroke: a prospective investigation. J Rehabil Med 2003;35(5):202-7.

7. Batchelor FA, Mackintosh SF, Said CM, Hill KD. Falls after stroke. Int J Stroke 20I2;7(6):482-90. DOI: | 0. I | | |/j. | 747-4949.20|2.00796. $\mathrm{x}$.

8. Weerdesteijn V, Niet MD, Van Duijnhoven H, Geurts AC. Falls in individuals with stroke. J Rehabil Res Dev 2008;45(8): I 195-2।3

9. Bandura A. Social cognitive theory: an agentic perspective. Annu Rev Psychol 200I;52(I):I-26. DOI: I0.I I46/annurev.psych.52.I.I.

10. Cho K, Yu J, Rhee H. Risk factors related to falling in stroke patients: a cross-sectional study. J Phys Ther Sci 20|5;27(6):|75|-3. DOI: I0.1589/jpts.27.175।.

II. Dewan N, MacDermid JC. Fall Efficacy Scale-International (FES-I).J Physiother 2014 Mar;60(I):60. DOI: 10.1016/j.jphys.2013.12.014.

12. Perell KL, Nelson A, Goldman RL, Luther SL, Prieto-Lewis N, Rubenstein LZ. Fall risk assessment measures: an analytic review. Gerontol A Biol Sci Med Sci 200I;56(I2):M76I-6.

I3. Li F, Fisher KJ, Harmer P, McAuley E. Delineating the impact of Tai Chi training on physical function among the elderly. Am J Prev Med 2002;23(2):92-7.

14. Pakistan Stroke Society. Information about Stroke. [Accessed on: October 02, 2018]. Available from URL: http://www.pakstroke.com/

15. Schmid AA, Arnold SE, Jones VA, Ritter MJ, Sapp SA, Van Puymbroeck M. Fear of falling in people with chronic stroke. Am J Occup Ther 2015;69(3):6903350020. DOI: 10.50I4/ajot.20I5.016253.

16. Lamb SE, Ferrucci L, Volapto S, Fried L, Guralnik JM. Risk factors for falling in home-dwelling older women with stroke: the Women's Health and Aging Study. Stroke 
2003;34(2):494-50I.

17. Mackintosh SF, Hill KD, Dodd KJ, Goldie PA, Culham EG. Balance score and a history of falls in hospital predict recurrent falls in the 6 months following stroke rehabilitation. Arch Phys Med Rehabil 2006;87(I2):I583-9. DOI: 10.1016/j.apmr.2006.09.004.

18. Yates JS, Lai SM, Duncan PW, Studenski S. Falls in communitydwelling stroke survivors: an accumulated impairments model. J Rehabil Res Dev 2002;39(3):38594.

19. Belgen B, Beninato M, Sullivan PE, Narielwalla K. The association of balance capacity and falls selfefficacy with history of falling in community-dwelling people with chronic stroke. Arch Phys Med Rehabil 2006;87(4):554-6I. DOI: 10.1016/j.apmr.2005.12.027.

20. Persson CU, Kjellberg S, Lernfelt B, Westerlind E, Cruce M, Hansson PO. Risk of falling in a stroke unit after acute stroke: The Fall Study of
Gothenburg (FallsGOT). Clin Rehabil 2018;32(3):398-409. DOI: 10.1177/0269215517728325.

21. Schinkel-Ivy A, Inness EL, Mansfield A. Relationships between fear of falling, balance confidence, and control of balance, gait, and reactive stepping in individuals with subacute stroke. Gait Posture 2016;43:I54-9. DOI: 10.1016/j. gaitpost.2015.09.015.

22. Panel on Prevention of Falls in Older Persons AGS, Society BG. Summary of the updated American Geriatrics Society/British Geriatrics Society clinical practice guideline for prevention of falls in older persons. J Am Geriatr Soc 20 I I;59(I): 148-57. DOI: $10.1 \mid I I / j .1532-5415.2010$. 03234.x.

23. Cumming RG, Salkeld G, Thomas M, Szonyi G. Prospective study of the impact of fear of falling on activities of daily living, SF-36 scores, and nursing home admission. J Gerontol A Biol Sci Med Sci 2000;55(5):M299-305.
24. Batchelor FA, Hill KD, Mackintosh SF, Said CM, Whitehead CH. Effects of a multifactorial falls prevention program for people with stroke returning home after rehabilitation: a randomized controlled trial. Arch Phys Med Rehabil 2012;93(9): I64855. DOI: 10.1016/j.apmr.20I2. 03.03I.

25. Tsai S-F, Yin J-H, Tung T-H, Shimada T. Falls efficacy among stroke survivors living in the community. Disabil Rehabil 2011;33(1920):I785-90. DOI: $10.3109 / 09638$ 288.2010 .546938$.

26. Goh H-T, Nadarajah M, Hamzah NB, Varadan P, Tan MP. Falls and fear of falling after stroke: a case-control study. Phys Med Rehabil (PM R) 2016;8(I2): I I73-80. DOI: I0.1016/ j.pmrj.2016.05.012.

27. Afridi A, Maqbool S, Malik AN. Relationship between fear, fall \& balance in community dwelling older adults relationship between fear, fall \& balance in community dwelling older adults. Pak J Neurol Sci 20I5; 10(2):3.

\section{AUTHORS' CONTRIBUTIONS}

Following authors have made substantial contributions to the manuscript as under:

NR: Conception and study design, acquisition, analysis and interpretation of data, drafting the manuscript, final approval of version to be published.

AF: Study design, critical review, final approval of version to be published.

MAA: Acquisition of data, drafting the manuscript, final approval of version to be published.

ST: Analysis and interpretation of data, critical review, final approval of version to be published.

Authors agree to be accountable for all aspects of the work in ensuring that questions related to the accuracy or integrity of any part of the work are appropriately investigated and resolved.

CONFLICT OF INTEREST
Authors declared no conflict of interest
GRANT SUPPORT AND FINANCIAL DISCLOSURE
NIL

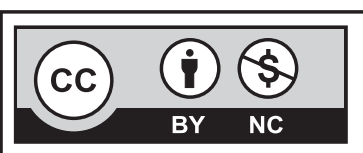

This is an Open Access article distributed under the terms of the Creative Commons Attribution-Non Commercial 2.0 Generic License.

KMUJ web address: www.kmuj.kmu.edu.pk

Email address: kmuj@kmu.edu.pk 